\title{
Pulmonary Hydatid Cysts Causing Massive Hemoptysis and Hydatoptysis Treated Surgically: A Case Report and Review of Literature
}

\author{
Ikram Chaudhry*, Ahsan Cheema, Hadi Mutairi, Miral Mashhour, Alaa AL Sharif, Shoukat Bojal and MS \\ AlQahtani
}

Department of Thoracic Surgery, Pathology and Hepatobiliary Surgery, King Fahad Specialist Hospital Dammam, Saudi Arabia

Submission: May 23, 2018; Published: May 30, 2018

*Corresponding author: Ikram ul haq Chaudhry, Department of Thoracic Surgery, Pathology and Hepatobiliary Surgery, King Fahad Specialist Hospital Dammam, Saudi Arabia, Email: drihc007@gmail.com

\begin{abstract}
A 52 years old male nonsmoker, presented with a history of shortness of breath, cough, hemoptysis and upper right upper quadrant abdominal pain for the last one month. No history of loss of weight or appetite. Patient was diagnosed six months ago as hydatid disease of liver and lung and he was commenced on oral scolicidial agent Abendazole by referring hospital. Computed tomographic scan of thorax and abdomen Demonstrated large bilateral pulmonary and hepatic cysts with typical radiological findings of hydatid cyst. Pulmonary cysts were excised by staged procedure and later on hepatic cyst were drained by interventional radiologist.
\end{abstract}

Keywords: Echinococcus granuloses liver; Lung; Hemoptysis; Hypertonic saline; Surgery

\section{Background}

Parasitic infestation by Echinococcus Granuloses was described by Rudolphy in 1808 as a hydatid cyst also this is known as echinococcosis and hydtasois [1]. There are four other species of Echinococcus which can affect human but among all

Echinococcus Granulosus is the most common cause of zoonotic parasitic infection (Table 1). Epidemiologically, this disease prevails almost all over the world but there are endemic areas as Australia, New Zealand, South and Central America, Middle East, Sub Saharan Africa, Russia, China, Turkey [2,3].

Table 1: Epidemiological features of different Echinococcus species.

\begin{tabular}{|c|c|c|c|c|}
\hline \multicolumn{1}{|c|}{ Species } & Geographical & Human Infection & Definite Host \\
\hline E Granulosus & All over the world & Common in human & Dog and other Canines & $\begin{array}{c}\text { Sheep, goats cattle, camels, } \\
\text { horses }\end{array}$ \\
\hline E Multiloculariari & $\begin{array}{c}\text { Russia, western China, } \\
\text { Japan, America, Africa) }\end{array}$ & $\begin{array}{c}\text { Less common infection in } \\
\text { human but can be severe, } \\
\text { limited to animal hosts } \\
\text { mostly }\end{array}$ & $\begin{array}{c}\text { Primarily dogs, wolves, } \\
\text { coyotes, cats }\end{array}$ \\
\hline E Vogeli & Central and South America & Intermediate & Wild dogs and Canines & Rodents. peacocks \\
\hline E Oligarthrus & Central and South America & Rare cases reported & Wild animals Pumas, \\
Jaguars
\end{tabular}

\section{Case}

A 52 years old male smoker presented to our tertiary care hospital with history of cough and hemoptysis. He was diagnosed six months ago in the referral hospital as case of hydatid disease of lung and was commenced on Albendazole $800 \mathrm{mg}$ daily. He had scattered hemoptysis for 3-4 times in a month but prior to admission he had massive hemoptysis. On clinical examination he had dyspnea with the respiratory rate of $24 / \mathrm{min}$, no cyanosis or jaundice, breath sounds were decreased 
over right hemi thorax. Laboratory tests revealed Hemoglobin (8gm/dl), liver enzymes Alanine Transaminase (ALT) 28U/lit Aspartate Transaminase (AST) 16U/lit, Alkaline phosphatase $300 \mathrm{U} /$ lit. Chest radiograph and CT scan of thorax and upper abdomen showed large bilateral pulmonary and hepatic cysts. Immunoglobulin $\mathrm{G}$ for echinococcus was positive. As the patient had massive hemoptysis and was symptomatic urgent surgery was planned. Surgical approach was right thoracotomy and we found a very large cyst densely attached and compressing the lung parenchyma. A purse string suture was placed and in the center of cyst and surrounding lung tissues were covered with gauze soaked in hypertonic $14 \%$ saline. A $14 \mathrm{~F}$ catheter was inserted in the cyst and tightly snugged to avoid any spillage then $200 \mathrm{ml}$ of $14 \%$ hypertonic saline was installed in the cyst cavity and left for five minutes after that fluid was sucked, catheter was removed and purse suture snugged. With meticulous dissection cyst was removed in total sparing the lung parenchymal tissues (Figures 1 \& 2). The left side cysts were removed as staged procedure after four weeks in similar fashion. Histopathology report showed dead daughter cysts and no live parasite (Figure 3).

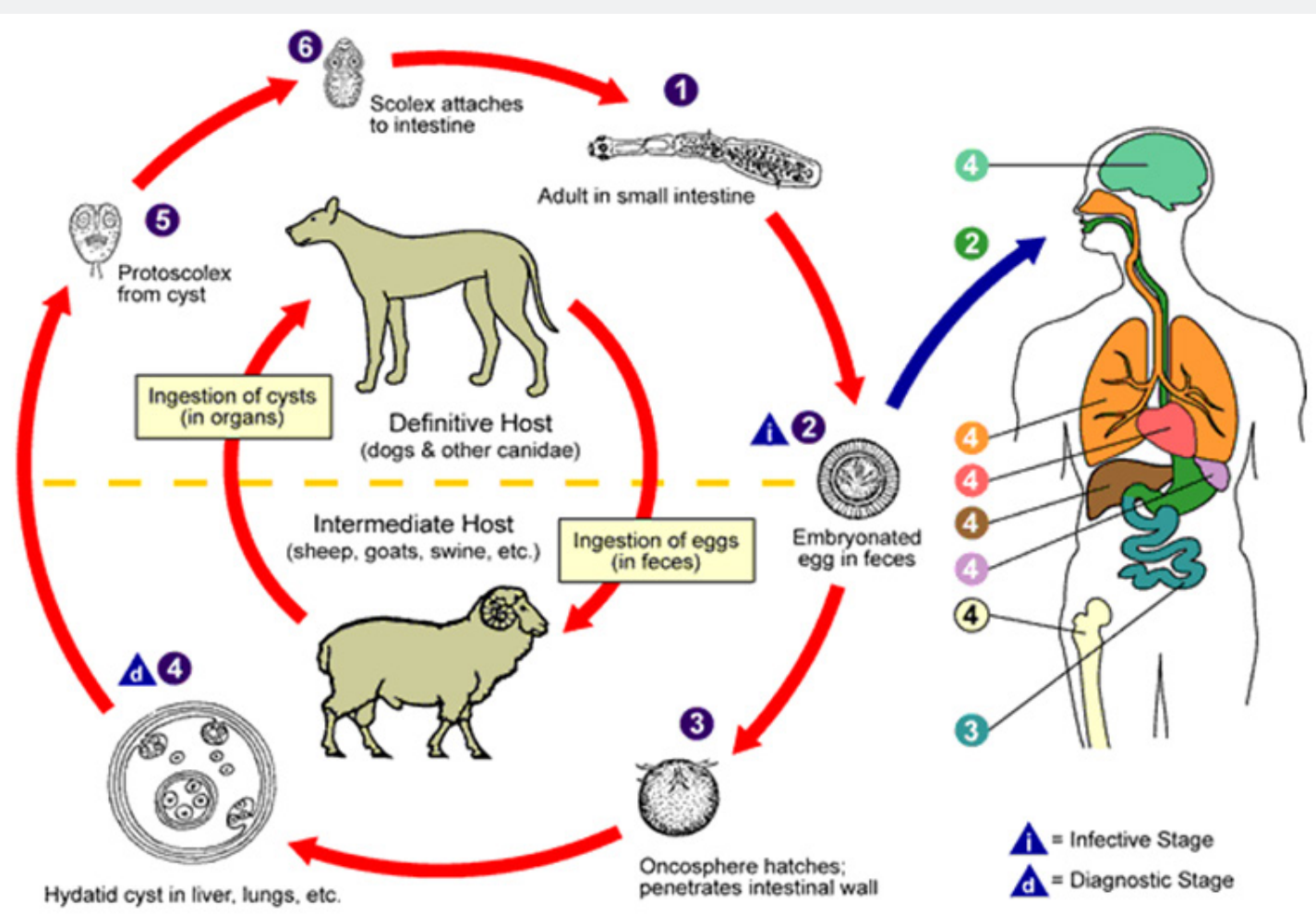

Figure 1: Lifecycle of Echinococcus Granuloses (Tapeworm) and effected human organs. (CDC Center for Disease Control and Prevention).

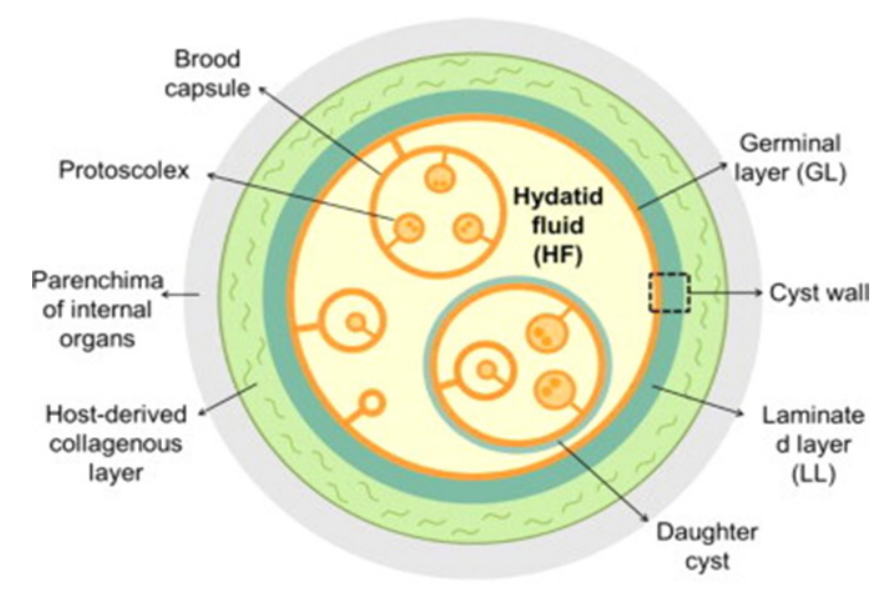

Figure 2:Trilayer structure of the Hydatid Cyst. 

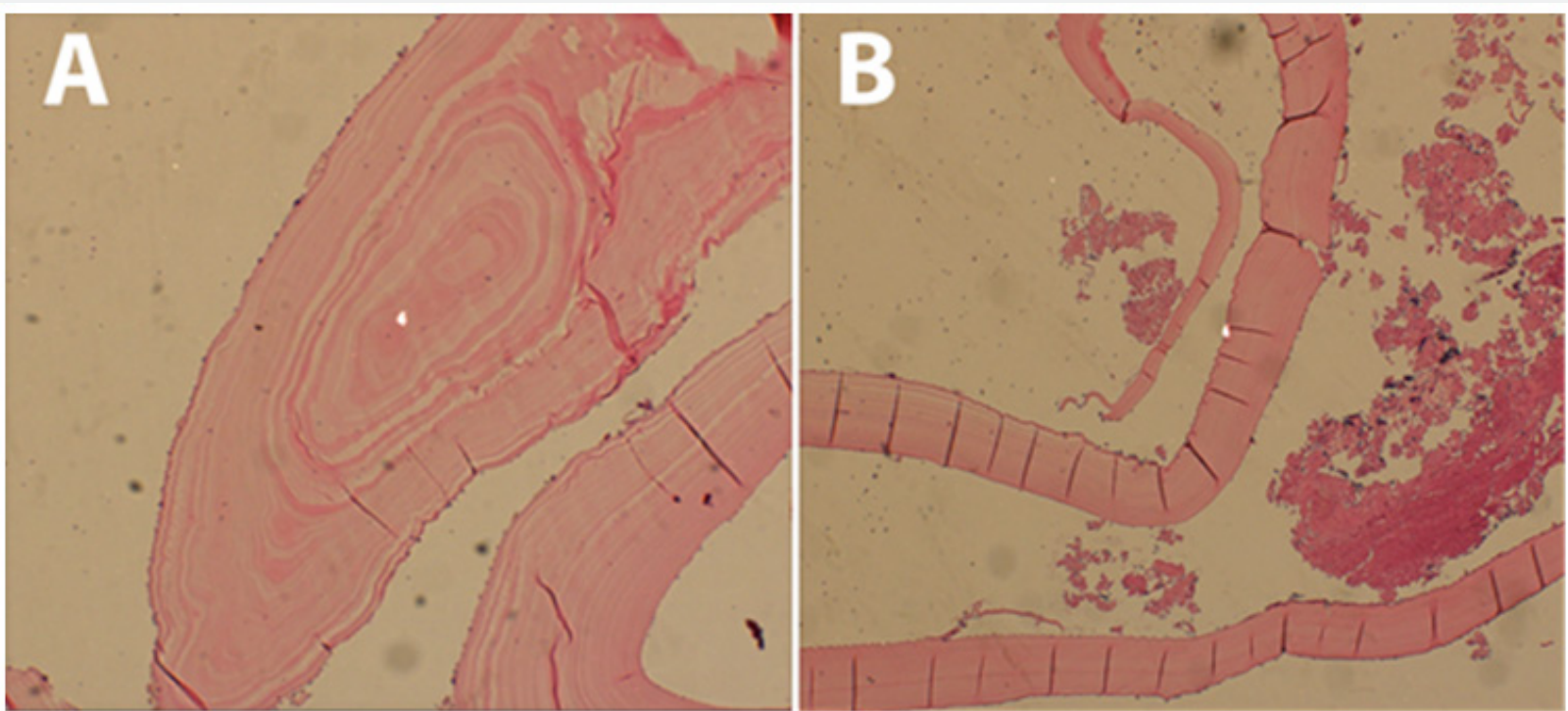

Figure 3: (A) Cyst cavity showing a germinal layer (B) H\&E 10 X showing Cyst wall.

\section{Discussion}

Echinococcosis also known as hydatisosis is the most common parasitic disease caused by larval cestodes. This parasite harbors in two hosts: primary and intermediate to complete its life cycle. Livestock animals like sheep, goat, horse, pigs, camels as well as humans are intermediate host while the Carnivorous animals like wolves, dogs, are definite host (Figure 4A-4F). Humans are infected accidently by ingesting the vegetables, fruits and water contaminated by soil with dog stool containing eggs. Echinococcus eggs can survive for a year outside in the atmosphere and are the main source of contamination
[4-6]. On ingestion eggs hatch to oncosphere larva in the small intestine thereafter, enter in to the blood stream and is carried to the liver by portal circulation or can by pass to pulmonary system and then develop to metacestodes. These fluid filled cysts are composed of hundreds of protoscolices, which are the source leading to formation of daughter cysts or mature worm (2-3 mm long). This life cycle is usually completed in 2-7 weeks. Human to human spread is not possible as carnivores' (definite host) is required to complete the life cycle. Hydatid cysts are tri layers, (pericyst, laminated and germinal) filled with nutritious fluid that promote larval growth $[7,8]$ (Figure 5).

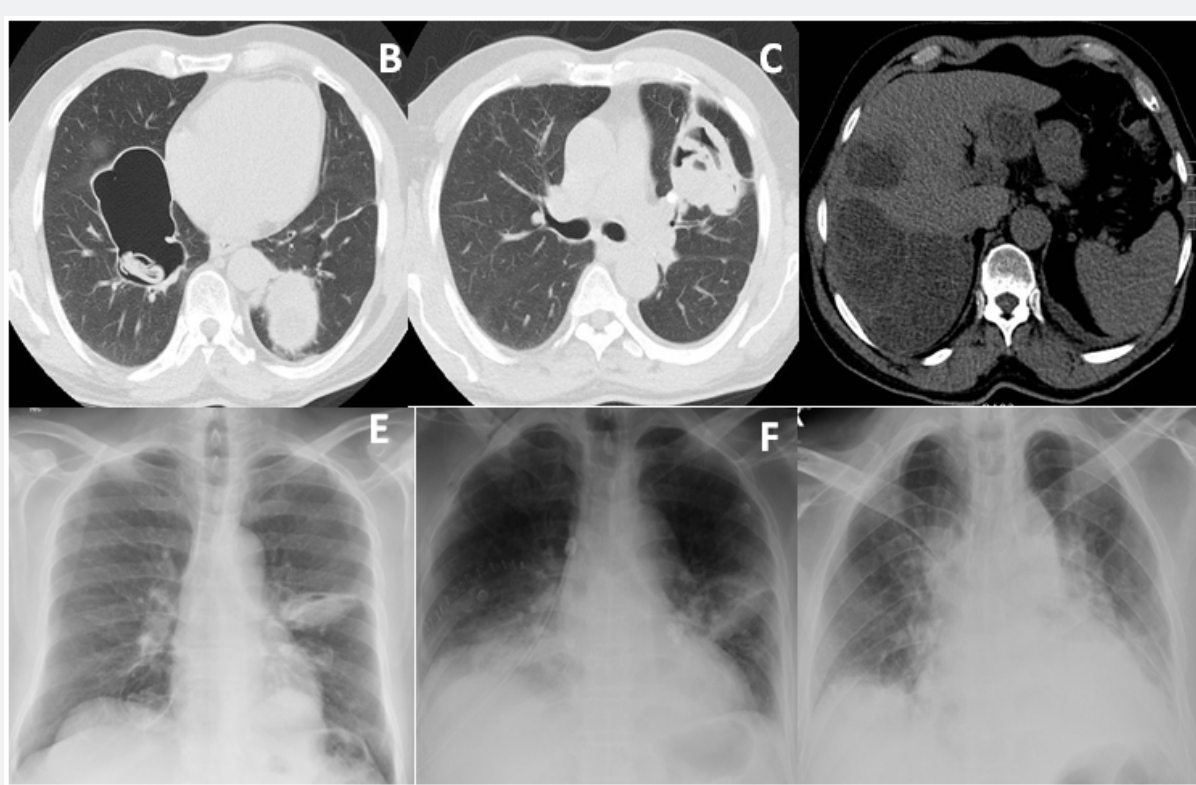

Figure 4: (A) CT Scan of Thorax showing a large cystic lesion in the Right lung. (B) CT Scan of Thorax showing a large cystic lesion in the Left lung. (C) CT Scan of Liver shows multiple cystic lesions. (D) Pre-operative chest X-ray. (E) Chest X-ray after right cyst excision. (F) Chest X-ray after bilateral staged thoracotomy. 


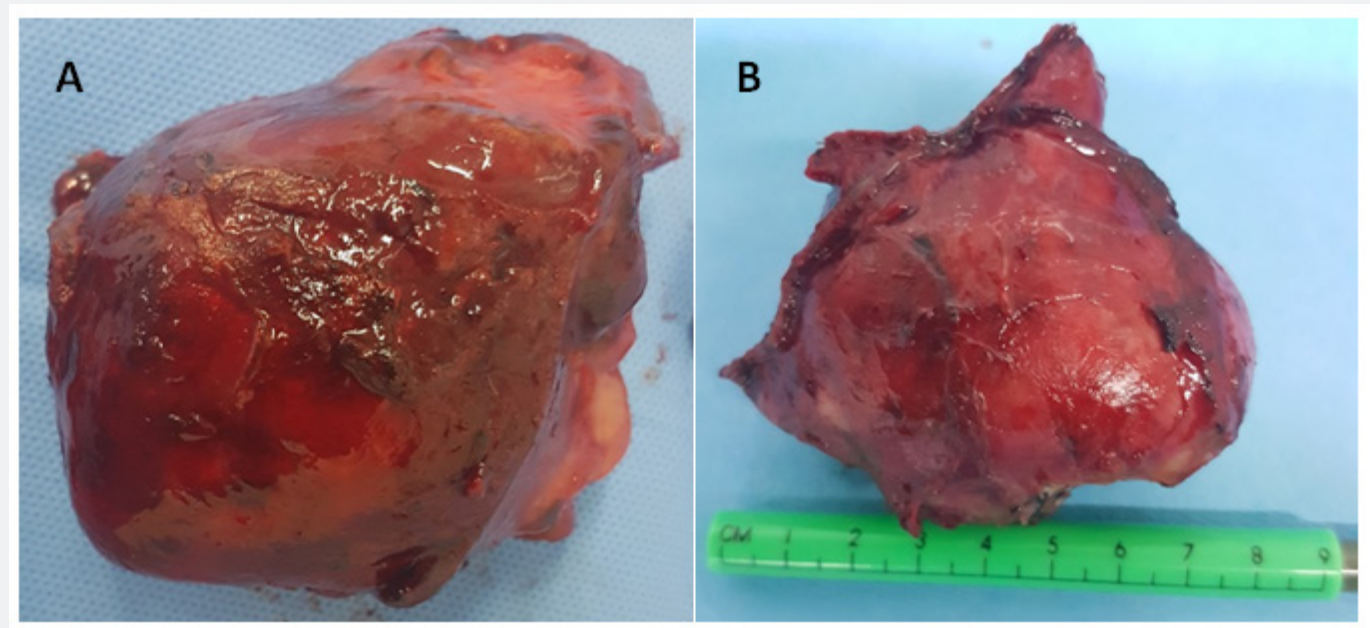

Figure 5: (A) Macroscopic view of the Right Hydatid cyst after excision.

(B) Left Hydatid cyst after excision.

The best diagnostic modality is imaging chest x-ray and CT scan of thorax and abdomen $[9,10]$. Serological methods, Weinberg complement fixation and Casoni tests were used in the past and their yield is very poor. ELISA and IHA are most widely used serological tests [11]. Patients with pulmonary hydatid disease are initially asymptomatic. Most of the symptoms are either due to mass effect of cyst on neighboring structures or rupture of cyst leading to anaphylactic reaction, hemoptysis, hydatoptysis, infection, pneumothorax and empyema (Table 2). Clinically patient can present with chest pain, fever, tachycardia, hemoptysis, and hydatoptysis. Pulmonary hydatid cysts increase in size faster than in other parts of body probably due to elastic nature of lungs and negative intrathoracic pressure [12-14].

Treatment is chemotherapy and surgery. The medical treatment is very beneficial in patients with multisystem (disseminated) disease and can be given as neodjuvant therapy or adjuvant therapy in patients at risk of spillage during the surgery. The commonly used chemotherapeutic drugs are Mebendazole, Albendazole, Benz imidazole and Praziquantal. Albendazole is preferred because of its better bioavailability and the dose is $15 \mathrm{mg} / \mathrm{kg}$ body weight per day in two daily doses approximately $800 \mathrm{mg}$ daily dose for minimum 3-6 months. It is not recommended in pregnancy particularly in first trimester due to its teratogenicity [15-18]. Horton et al. [19] treated 500 patients of Echinococcosis giving those $800 \mathrm{mg}$ of Albendazole daily two and half cycles with 14 days interval. After evaluation of 250 patients only 47 required surgery and resected specimen demonstrated that only five patients have viable parasite. Recurrence rate in patients who received preoperative Albendazole as compared to those who did not receive Albendazole was $18.75 \& 4.16 \%$ respectively. In medical literature Little et al. [20] reported recurrence rate of 22\%, Mottaghlan and sadi observed $11.3 \%$. Medical treatment alone is not enough to eradicate the disease once there are cystic lesions in lung and liver $[19,20]$.
Radical Surgical resection of host tissues and entire cyst is mandatory if patient is symptomatic or any signs of infection or invasion in to surrounding structures. Postoperative chemotherapy for 1-2 years is recommended. Surgical approach is designed according to the location of the cysts. Most common surgical approaches are thoracotomy, median sternotomy and video assisted thoracoscopic resection. The basic surgical principal is that spillage of cyst contents should be avoided and adjacent tissues should be packed with gauze soaked in hypertonic saline solution $(15 \%, 20 \%)$ to avoid contamination. In case of cyst rupture during surgery or if cyst is infected, after the removal of germinal layer its recommended to wash the cyst cavity with hypertonic saline solution [21]. Dekak et al. [22] reported 202 patients who underwent surgery out of 422 cases. Enucleation, capitonage, segmentectomy, and lobectomy were the procedures performed [22]. Biswas \& Burhan et al. [23] reported 26 and 24 cases respectively which were treated surgically. Ashok et al. [24] reported 33 cases out of 72 who required surgery [24].

Liver is the most common site of hydatid cyst formation, right lobe and left lobes are affected $60-75 \%$ and $20 \%$ respectively. Hepatic cysts generally remain asymptomatic for long time. The most common complication is intrabillary rupture $3-17 \%$ or rarely can rupture in to pericardial, pleural or peritoneal cavity, and neighboring organs in $20-50 \%$ of cases. Sometimes cysts develop secondary bacterial or fungal infection. The best diagnostic modality is Ultrasound and Spiral CT scan. ERCP can be helpful for diagnosis of biliary rupture or communication. Liver hydatid cyst rupture can be categorized as contained, communicating or direct. Reported incidence of communicating rupture in to biliary system is $44-64 \%$ [25]. The patient with intrabillary rupture present with right upper quadrant pain, obstructive jaundice, fever, cholangitis and sepsis (Table 2). There are multiple treatment modalities for the management of liver hydatid disease and surgery is reserved for complicated 
cysts. Rupture of the cyst into adjacent organs, complicated with biliary fistula, compression of adjacent vital structures and cysts with infection or hemorrhage require surgical intervention. Surgery is also recommended for cysts with many daughter vesicles that are not amenable to percutaneous treatment (WHO stage CE2 and CE3b) [26] (Table 3). If the cyst diameter is more than $10 \mathrm{~cm}$ and or percutaneous facilities are not available then surgery is advisable. The other management options recommended by WHO are drug therapy (Albendazole) for stage CE1 and CE3 a provided the cysts are less than $3 \mathrm{~cm}$. If because of any reason medical management is not feasible then percutaneous treatment with puncture, aspiration, injection and respiration (PAIR) is the alternative. Combination treatment with PAIR and Albendazole is recommended for stage CE1 and CE3 that are more than $5 \mathrm{~cm}$ in size [27-29].

Table 2.

\begin{tabular}{|c|c|c|c|}
\hline \multicolumn{2}{|c|}{ Hepatobiliary } & \multicolumn{2}{|c|}{ Pulmonary } \\
\hline Symptoms & Complications & Symptoms & Complications \\
\hline Right Upper & Rupture: & & Mass Effect Of The Cyst \\
Quadrant & Intrabillary \\
Abdominal & Pericardial & Chest Pain \\
Pain With & Peritoneal \\
Rebound & Pleural & & Rupture Of The Cyst: \\
Tenderness & Adjacent Organs & Lung \\
\hline & Infection: & Trachea \\
\hline Hepatomegaly & Bacterial, & & Pericardium \\
\hline Fever With Chills & Hemorrhage & Tachycardia & Anaphylactic Reaction \\
\hline Cholangitis & Biliary Fistula & Hemoptysis & Hemoptysis \\
\hline Sepsis & & Hydatoptysis & Hydatoptysis \\
\hline Anorexia & & & Lung Infection \\
\hline Weight Loss & & & Pneumothorax \\
\hline Nausea, Vomiting & & & Bronchopleural Fistula \\
\hline Obstructive Jaundice (Late) & & & Empyema \\
\hline
\end{tabular}

Table 3.

\begin{tabular}{|c|c|c|c|}
\hline $\begin{array}{c}\text { WHO-IWGE } \\
\mathbf{2 0 0 1}\end{array}$ & Gharbi 1981 & Description & Stage \\
\hline CE 1 & Type I & Unilocular, unechoic cystic lesion with double line sign & Active \\
\hline CE 2 & Type III & Multiseptated, "rosette-like" "honeycomb" cyst & Active \\
\hline CE 3 A & Type II & Cyst with detached membranes (water-lily sign) & Transitional \\
\hline CE 3 B & Type III & Cyst with daughter cysts in solid matrix & Transitional \\
\hline CE 4 & Type IV & Cyst with heterogeneous hypoechoic/hyperechoic contents. \\
\hline CE 5 & Type V & Solid cyst with calcified wall & Inactive \\
\hline
\end{tabular}

\section{Conclusion}

In conclusion we treated a patient who had simultaneous hepatic and bilateral pulmonary hydatid cysts who presented with hemoptysis and right abdominal upper quadrant pain. The pulmonary hydatid cysts were resected as staged procedure and liver cysts were treated with PAIR and Albendazole therapy for six months. Our improvised technique of installation of hypertonic saline in the cyst prior to surgical dissection is effective and safe.

\section{Acknowledgement}

The authors acknowledge Rana Jaman Al Ghamdi for preparation of transcription. 


\section{References}

1. Rudophi KA, Entozoorum Siv (1808) Vermimum Intestinalium. Hstoria Naturalis VolI 247 Amsterdam. In: Taberna, et al. Atrium.

2. RI Shalabi, AK Ayed, M Amin (2002) 15 Yyears in surgical management pulmonary hydatidosis. Annals of Thoracic and Cardiovascular Surgery. 8(3): 131-134.

3. G Gorssi, MG Lastilla A, Teggi (1991) 420 patients with hydatid cust: observation of clinical picture. Arch Hydatid 30: 1021-1025.

4. Ramos G, Orduna A, Garcia Yuste (2001) Hydatid cyst of lung: diagnosis and treatment. World J Surg 25(1): 46-47.

5. Ekim H, Ozbay B, Kurnaz M, Tuncer M, Ekim M (2009) Managment of complicated giant thoracic hydatid disease. Med Sci Monit 15(12) 600-605.

6. Todorov T, Boeva (2000) Echinicoccosis in chidren and adolescents in Bulgaria: A comparative study. Ann Trop Med Parasitol 94(2): 135-144.

7. Sarkar M, Pathenia R, Jhobta A, Thakur BR, Chopra R (2016) Cystic pulmonary hydatidtosis. Lung India 33(2): 179-191.

8. Rrfik M, Mehmet N Durmaz B, Egri M (2002) Determination of some biochemical parameters in hydatid cyst fluids. Erciyes Med j 24: 10-13.

9. Dogan R, Yuksel M, Cetin G, K Süzer, M Alp, et al. (1989) Surgical treatment of hydatid custs of the lung :report on 1055 patients. Thorax 44(3): 192-194.

10. Koul PA, Koul AN, Wahid A, Mir FA (2000) CT in pulmonaryhdatis disease:unusual appearances. Chest 118(6): 1645-1647.

11. Force L, Toress JM, Carillo A, Busca J (1992) Evaluation of eight serological tests in the diagnosis of human echinococcosis and follow up. Clin infest Dis 15(3): 473-480.

12. R Morar, C Feldman (2003) pulmonary echinococcosisi. Eur Respir J 21: 1069-1077.

13. A Sadrizadeh, SZ Haghi, SHF Masoum, R Bagheri, MN Dalouee (2014) Evaluation of the effects of pulmonary hydatid cyst location on the surgical technique approaches. Lung India 31(4): 361-365

14. Y Ozsurekci, AO Parlakay, AB Cengiz (2012) A typical presentation in hydatid disease: Hemoptysis. Turkiya Parazitoloji Dergisi 37(1): 69-70.

15. S Toleti, M Subbarao, P Dawarabu (2012) Hydatid disease of the lung presenting with heamoptysysis and simulating lung abscess. Trop Parasitol 2(1): 69-70.

16. Anadol D, Ozcelik U, Kipper N, Goceman A (2001) Treatment of hydatid disease. Paediatr Drugs 3(2): 123-135.
17. Bartoloni C, Tricerri A, Guidi L, Gambassi G (1992) The efficacy of chemotherapy with mebendazole in human cystic echininococcuc: long term follow up of 52 patents. Ann Trop Med Parasitol 86(3): 249256.

18. Galanakis E, Bessis S, Pappa C, Nicolopoulos P, Lapatasanis P (1997) Treatment of complicated pulmonary echinococcosis with albendazole in chilhhod. Scand J Infect Dis 29(6): 638-640.

19. Cobo F, Yarnoz C, Sesma Be, Fraile P, Aizcorbe M, et al. (1998) Albendazole plud praziquantel verses albendazole alone as a preoperative treatment in intra-abdominal hydatisosis caused by Echinococcus granulosus. Trop Med Int Health 3(6): 462-466.

20. Horton RJ (1989) Chemotherapy of echinococcuc infection in man with albendazole. Trans R Soc Trop Med Hyg 83(1): 97-102.

21. Mottaghian Hassan, Sadi Farrok (1978) Postoperative recurrence of hydatid disease. Br J Surg 65(4): 37-42.

22. Mohammad Adahmashi, Mohamed Alassal, Ibrahim Kasab, Hany Elrakhawy (2016) Conservative surgical management for pulmonary hydatid cyst:Analysis and outcome of 148 cases. Can Resp jur 2016: 8473070 .

23. Dakak M, Yucel O, Kavaldi K (2009) Intrathoracic extrapulmonary hydatid cyst Review 33 case. Trakya uni Tip Fak Derg 26(2): 125-129.

24. Biswas B, Ghosh D, Bhattacharjee R, Ashis Patra, Subir Basuthakur et al. (2004) One stage management of hydatid cyst of lung and liver by right thoracotomy \& phrenotomy. indian Journal of Thoracic and Cardiovascular surgery. 20(2): 88-90.

25. Ashok Suryhanaji Gajbhiye, Mangla M, Sobak Malikchand M, Meshram, Amrish P, et al. (2013) Surgical management of pulmonary hydatid cyst. IOSR Journal of dental and medical sciences 6: 59-64.

26. Lt Col, S Anand, Brig, S Rajangopalan, Sqn Ldr, et al. (2012) Management of liver hydatid cysts- current perspectives Med journal of armed forces india 68(3): 304-309.

27. Gharbi HA, Hassine W, Brauner MW, Dupuch K (1981) Ultrasound examination of the hydatic liver. Radiology 139: 459-463.

28. Enrico Brunette, Peter Kern, Dominique Angele (2010) Acta tropical 114(1): 1-16

29. Dervenis C, Delis S, Avgerinos C, Madariaga J, Melicevic M (2005) Changing concepts in the management of liver hydatid disease. J Gastrointestinal Surg 9(6): 869-877.

Your next submission with Juniper Publishers will reach you the below assets

- Quality Editorial service

- Swift Peer Review

- Reprints availability

- E-prints Service

- Manuscript Podcast for convenient understanding

- Global attainment for your research

- Manuscript accessibility in different formats

( Pdf, E-pub, Full Text, Audio)

- Unceasing customer service

Track the below URL for one-step submission https://juniperpublishers.com/online-submission.php 